\title{
Sensitization to Common Ragweed in Southern Bavaria: Clinical and Geographical Risk Factors in Atopic Patients
}

\author{
Franziska Ruëffa Bernhard Przybilla ${ }^{a} \quad$ Annett Walker ${ }^{a} \quad$ Jennifer Gmeiner ${ }^{a}$ \\ Matthias Kramer ${ }^{b}$ Daniel Sabanés-Bovéc, $d$ Helmut Küchenhoff ${ }^{c}$ \\ Thomas Herzinger ${ }^{a}$ \\ Departments of a Dermatology and Allergology, ${ }^{b}$ Otorhinolaryngology-Head and Neck Surgery, and \\ 'Statistical, Consulting Unit, Department of Statistics, Ludwig-Maximilian University, Munich, Germany; \\ ${ }^{d}$ Institute of Social and Preventive Medicine, Biostatistics Unit, University of Zurich, Zurich, Switzerland
}

\section{Key Words}

Atopy $\cdot$ Ragweed $\cdot$ Aeroallergens $\cdot$ Sensitization

\begin{abstract}
Background: Sensitization to common ragweed (Ambrosia artemisiifolia) is associated with a variety of risk factors, which are incompletely defined. Our aim was to evaluate the association of a variety of clinical, geographical and demographical variables with ragweed sensitization and also to determine its frequency in southern Bavaria. Methods: In this cross-sectional multicentre study, we enrolled 977 patients with a documented or suspected atopic disease or food allergy. Data were collected on aeroallergen sensitization, age, sex, type and history of allergic disease, place of residence and potential local ragweed exposure. For this last variable, county ragweed cover was taken as a surrogate variable. Relative rates were calculated with multiple additive logistic regression models. Randomly selected patients with ragweed sensitization had a conjunctival provocation test. Results: According to skin prick tests, 190 patients (19.5\%) were sensitized to ragweed. The frequency of this finding increased significantly with a rising number of additional sensitizations. Other less important predictors for a ragweed sensitization were male gender, mugwort sensiti-
\end{abstract}

zation, food allergy and a maximum of complaints in September or October. County of residence, extent of local ragweed cover or type of residential area were without relevance. Of 48 sensitized patients, 26 (54.2\%) had a positive conjunctival provocation test. Discussion: Patients with multiple sensitizations may be more readily sensitized to a new aeroallergen. Local geographic or environmental conditions are presumably of minor importance for becoming sensitized to ragweed. The frequency of ragweed allergy among sensitized patients might be high.

Copyright $\odot 2012$ S. Karger AG, Basel

\section{Introduction}

There has been an increase in the prevalence of allergic rhinitis in many countries over the last two decades, especially in industrialized countries [1]. In the context of global warming, it is foreseen that the longer duration of the growing season will probably enhance higher pollen concentration stimulated by the rise of atmospheric $\mathrm{CO}_{2}$ [2]. The types of pollen responsible for symptoms vary widely with locale, climate and regional plantings [3]. In North America, common ragweed (Ambrosia artemisiifolia) is the prime cause of allergic rhinitis. One single

\section{KARGER}

Fax +4161306 1234

E-Mail karger@karger.ch

www.karger.com (c) 2012 S. Karger AG, Basel

$1018-2438 / 12 / 1591-0065 \$ 38.00 / 0$

Accessible online at:

www.karger.com/iaa
Correspondence to: Prof. Dr. Franziska Ruëf

Klinik und Poliklinik für Dermatologie und Allergologie

Allergiezentrum, Ludwig-Maximilians-Universität München

Frauenlobstrasse 9-11, DE-80337 München (Germany)

Tel. +49895160 6170, E-Mail Franziska.Rueff@ med.uni-muenchen.de 
plant alone may produce millions of ragweed pollen grains. Since the pollen grains are small $(18-22 \mu \mathrm{m})$ they are often involved in episodes of long-distance transport [4]. Very low concentrations such as $5-10$ pollen grains per cubic meter of air are sufficient to trigger allergic reactions in sensitive patients, and ragweed pollen may cause asthma much more frequently than other pollens $[5,6]$.

Originally, ragweed did not belong to the domestic flora in Europe, and was probably imported already in the 19th century by contaminated seeds from North America. Initially, only Hungary experienced considerable spreading of $A$. artemisiifolia around the early 1990s, when the abandonment of large-style collective agriculture resulted in large fields with concurrent ragweed invasion. Before the year 2000, the spread of ragweed and the consecutive sensitization in other European countries were reported to be of only minor importance, with the highest rates registered in certain regions of France (Rhone valley), Croatia, northern Italy, The Netherlands and the UK [7]. The spread of A. artemisiifolia plants in Germany occurred later, but was extremely fast; by 2007, the area infested in Germany was 10 times larger than that found in 2000 [8].

During the last decade, German authorities became increasingly aware of this change, and the question arose as to what extent the population in southern Bavaria might be exposed to a new allergen, and whether this increased exposure would mandate preventive measures such as plant eradication on a large scale. To get a preliminary idea of the dimension of the problem, the Bavarian State Ministry of the Environment and Public Health initiated this present cross-sectional study to document the regional frequency of ragweed sensitization in highrisk patients. In addition, by using a random sample, we attempted to estimate the frequency to become allergic to ragweed when sensitized. A further aim of the study was to identify clinical determinants for ragweed sensitization after adjusting to geographic or environmental confounders.

\section{Methods}

\section{Study Design}

Initiated by the Bavarian State Ministry of the Environment and Public Health, this is a cross-sectional cohort study performed in Bavaria (Munich and 3 smaller towns in Lower Bavaria and Swabia). The primary study outcome was the documentation of a ragweed sensitization. The study was designed to permit the detection of a 1.4-fold difference in the prevalence of a ragweed sensitization between 2 equal groups. A total of about 200 new cases of ragweed sensitization were required to give the study sufficient power to detect such an increase in frequency (2-sided type I error, 5\%; power, 90\%). Based on data from a neighbouring country (Vienna, Austria) [9], the frequency of ragweed sensitization among high-risk patients was assumed to be 200 per 1,000 patients, and hence the study had to collect at least 900 patients with a high risk for ragweed sensitization before the primary objective could be examined. The prospective data collection was approved by the Institutional Review Board of the Munich centre and each patient consented to participate in the study.

Collection of Data

Enrolment

Enrolment of patients began in October 2006 and completed by the beginning of 2009. Eligible were outpatients who were at least 18 years old and who presented with a suspected or documented, present or former atopic disease (allergic airway disease, atopic dermatitis) or food allergy. Diagnosis of diseases (allergic asthma, allergic rhinoconjunctivitis, atopic eczema and food allergy) followed specific guidelines $[3,10,11]$. In particular, food allergy was diagnosed if a patient presented with immediate-type symptoms (oral allergy syndrome and/or systemic anaphylactic symptoms) and simultaneously had a sensitization to the culprit food according to skin prick test results or demonstration of specific serum IgE. Patients were excluded if they were pregnant or suffering from severe comorbidities, or if they were not eligible for routine allergy testing because of contraindications $[10,11]$.

\section{Patient History}

History was documented in a questionnaire, which included information about the history of a potential allergic disease, medication and demographic data. We specifically recorded where the patient lived (by Bavarian county or by residential area, i.e. urban, suburban or rural). We also categorized patients according to their history of residential changes. Patients were divided into those who had never left the state of Bavaria before, those who had moved to Bavaria from another German state and those who had been living in an area with a presumably high ragweed exposure (e.g. North America, the former Yugoslavian states, Hungary, Poland, the Rhone valley, northern Italy) for more than 3 months. We wanted hereby to separate those patients who had just left Bavaria for a short time for recreational reasons from those who had been living abroad for a longer time for occupational or private reasons.

In addition, patients were classified according to the extent of ragweed cover in the county in which they were living. To do so, we used information kindly provided by the German Task Force for Biodiversity and Landscape Ecology [12]. County ragweed cover between 2006 and 2008 was described as the area $\left(\mathrm{m}^{2}\right)$ covered with ragweed plants. Seven different classes were possible: 0 , 1-99 m², 100-999 m², 1,000-4,999 m², 5,000-9,999 m², 10,000$49,999 \mathrm{~m}^{2}$ and $\geq 50,000 \mathrm{~m}^{2}$. The regional extent of ragweed cover was taken as a surrogate variable for ragweed allergen exposure. During the time of the study, only the former variable was available for evaluation in Bavaria.

For all patients with allergic airway symptoms, we recorded in detail: in which year symptoms had been noticed for the first time, during how many months of the year symptoms were present and in which months they reached their maximum. We also recorded gender, age and any anti-allergic medication due to allergic symptoms. 


\section{Data Accuracy}

Accuracy of data on the forms was ensured by the specific qualifications of research staff. All patients were assigned a unique code during the first hospital visit, and forms were transmitted to the Munich depository without identification of the patient. Each patient form was checked for completeness and plausibility by members of the Munich Advisory Board.

\section{Skin Prick Tests}

In all patients, single skin testing was performed by medical doctors using prick lancets and commercially available extracts obtained from ALK-Abelló (Hørsholm, Denmark). The following allergen sources (sensitization groups in parentheses) were tested: ragweed extract (A. artemisiifolia pollen), Dermatophagoides pteronyssinus and D. farinae (house dust mites), cat and dog (animal dander), grass mix and rye pollen (grass pollen), birch, alder, hazelnut, oak beech (tree pollen) and mugwort pollen. In addition, in patients from the Munich centre, skin prick tests with stinging nettle, ash, plantain and six molds (Alternaria alternata, Penicillium, Mucor, Rhizophus, Aspergillus and Cladosporium) could also be performed.

Since potency and probably also composition may differ, each patient from the Munich centre underwent 4 additional tests for ragweed sensitization using ragweed extracts from four other manufacturers (Allergopharma, Reinbek, Germany; HAL Allergy, Leiden, Netherlands; Allergy Therapeutics, Worthing, UK; Stallergenes, Antony Cedex, France). Histamine dihydrochloride $10 \mathrm{mg} / \mathrm{ml}$ was used as a positive control, diluent as a negative control. The procedure adopted for skin testing followed recommendations recently summarized by the Global Asthma and Allergy European Network (GA ${ }^{2}$ LEN) [13].

For statistical analysis, sensitizations to allergens from different animal hairs, trees, house dust mites and from grass or rye were combined into 1 class each, yielding - together with mugwort and ragweed sensitization - a total of 6 sensitization groups. For testing positive for an allergen class, a patient had to be sensitized to at least 1 allergen of this class. In patients from Munich, the additionally tested allergens (stinging nettle, ash, plantain and molds) increased the maximum number of sensitization groups to 10 .

\section{Measurement of Ragweed-Specific IgE Concentration}

Only patients from the Munich centre could be studied. A 5 -ml blood sample was taken at the first patient visit to determine the concentrations of ragweed-specific IgE antibodies. Measurements were done by CAP-FEIA (ImmunoCAP 250, Phadia, Freiburg, Germany). After centrifugation, aliquots of $2 \mathrm{ml}$ of serum were frozen at $-20^{\circ} \mathrm{C}$ and stored until all samples were collected, to allow a measurement by the same batch of test reagents. Results were given in kU/l.

\section{Conjunctival Provocation Tests}

Patients of the Munich centre who were found to be sensitized to ragweed, did not present with rhinoconjunctivitis and did not wear contact lenses, we performed a conjunctival provocation test according to a slightly modified method of Möller et al. [14]. Three subjects without ragweed sensitization served as controls. We used a commercial preparation for the challenge test (HAL Allergy) and made serial dilutions with the control solution (containing $5 \%$ phenol) provided by the manufacturer to produce 4 solutions at concentrations of $0.1,1.0,10$ and $100 \%$ of the test solution. We used the diluent as the negative control. We started by placing a single drop of the control solution into the right conjunctival sac. We then placed single drops of successively stronger solutions in the left conjunctival sac at 20-min intervals, each step in the test sequence being contingent on a negative response in the immediately preceding test. We regarded any test as positive and concluded the procedure if, after inspection for redness and inquiry about eye itch, eye weeping, eye burning, nose dripping or nose blockage (score: mild $=1$, moderate $=2$ and severe $=3$ ), a total score of 5 was reached.

\section{Outcome}

The primary outcome of the study was a sensitization to ragweed. This was diagnosed if a patient had a positive skin reaction to ragweed after the ALK-Abelló allergen. For a separate analysis in a subgroup (patients from the Munich centre), ragweed sensitization was also diagnosed if we had observed positive reactions to 2 extracts manufactured by a different company or if IgE measurements revealed ragweed-specific IgE antibodies $>0.35 \mathrm{kU} / \mathrm{l}$.

\section{Statistics}

Multiple logistic regression was used to assess the statistical association of ragweed sensitization with several covariates of interest. For categorical covariates, coefficients for all categories except the reference category were included in the regression models. While these were estimated without constraints for nominal covariates with unordered categories, those of neighbouring categories were assumed to be similar for the ordinal covariates with ordered categories. The effects of continuous covariates and varying coefficients were modeled non-linearly [15]. For the spatial county covariate it was assumed that neighbouring counties have similar coefficients.

The models were estimated with Bayesian inference [15] through the special software BayesX [16]. Standard prior distributions were used for all model parameters. For linear effects, posterior means as point estimates and posterior $95 \%$ credible intervals were derived. In addition, simultaneous $95 \%$ credible bands were derived for non-linear effects. A relevant statistical association was diagnosed when the reference odds ratio 1 was not included in the $95 \%$ credible intervals, or when the posterior probability of a positive association with a covariate was $>95$ or $<5 \%$, respectively.

A baseline confounder model was selected by stepwise optimization of the deviance information criterion (DIC) by eliminating covariate terms or by simplifying non-linear terms to linear terms [17]. In this model, mugwort sensitization was also part of the covariate 'number of co-sensitization classes'. Like this, a specific mugwort association could be separated from the association resulting from cross sensitization. To evaluate allergic airway diseases, allergic asthma and allergic rhinoconjunctivitis were combined into one single variable. To be classified as suffering from an allergic airway disease, a patient had to present either with allergic asthma or allergic rhinoconjunctivitis, or both. The effect of this compound variable was modelled on the basis of a varying coefficient depending non-linearly on the duration of the disease. No attempts were made to evaluate different elicitors of food allergy separately.

To examine local geographical effects, we then tested 4 different final models. In the first 2 models, we estimated an association 


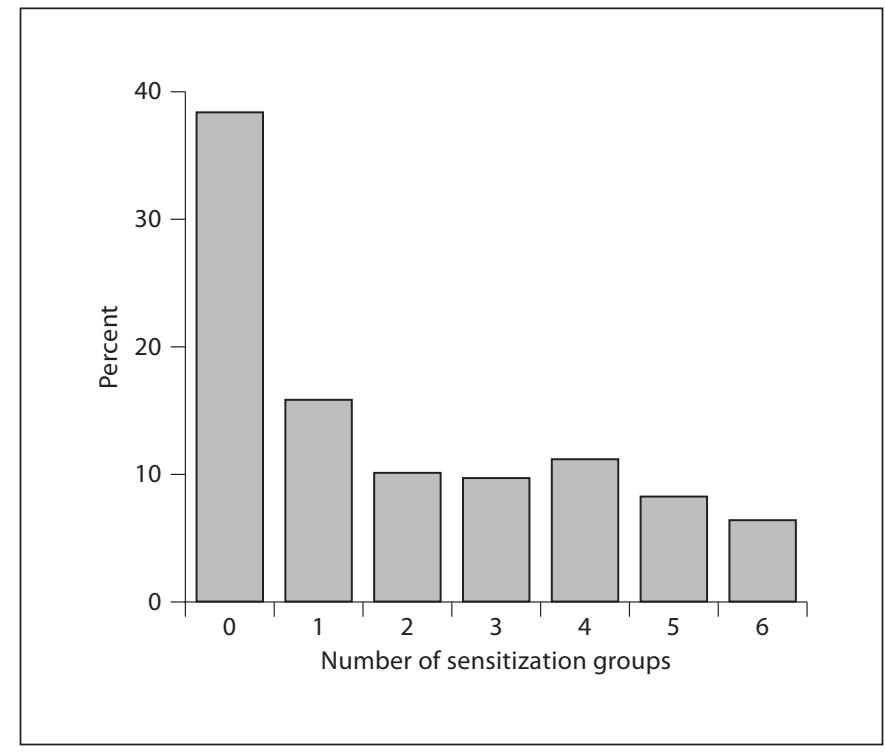

Fig. 1. Frequency distribution of polysensitization to 6 groups of aeroallergens (house dust mites, animal dander and pollen from grasses, trees, mugwort and $A$. artemisiifolia) in patients with documented or presumed atopy and/or food allergy $(\mathrm{n}=977)$.

of the categorical covariate 'county of residence' or of the ordinal covariate 'extent of county ragweed cover' with ragweed sensitization. To evaluate the variable 'extent of county ragweed cover', classes 2 and 3, and 6 and 7 of that variable (see Methods) were combined into 2 classes, because only 1 patient was living in each of a class 2 or 7 county. The models contained an additional binary covariate adjusting for unobserved heterogeneity between the Munich centre and the regional centres.

Apart from 71 counties, the state of Bavaria includes 25 'county-free' cities. In the model, in which we estimated an association of the categorical covariate 'county of residence', patients living within Munich city-limits were used as the reference population (the city of Munich does not belong to a county). The remainder were analyzed according to the county or to county-free city they were living in.

The last 2 models were only estimated for patients of the Munich centre, for whom a more subtle analysis was possible. For these models, a separate construction was necessary because of differences in the definition of the covariate 'number of aeroallergens to which the patient was sensitized' and because of the dependent variable 'ragweed sensitization'. We either incorporated the variable 'residential area' or the variable 'extent of county ragweed cover' into the baseline confounder model to examine whether the local environment was of importance. In the model, in which we estimated an association of the categorical covariate 'residential area', patients living within Munich city-limits were again used as the reference population. The remainder were analyzed according to whether they were living in Munich county (i.e. the suburban area surrounding Munich city-limits) or in the areas outside of it.

\section{Results}

\section{Clinical Characteristics of the Cohort}

Originally, 1,272 subjects were enrolled in the study. In compliance with the exclusion criteria, a total of 977 patients were available for the evaluation of ragweed sensitivity and its predictive variables. The median patient age in the cohort was 43 years (interquartile range $30-56$ ) and the majority of patients were female (62.0\%). An atopic disease or food allergy could be diagnosed in $63.9 \%$ of the patients. Among the 977 patients, $49.6 \%$ were suffering from allergic asthma or rhinoconjunctivitis, $25.9 \%$ presented with atopic eczema and $29.0 \%$ had a food allergy (tree nuts $16.8 \%$, pip and/or stone fruits $15.4 \%$, celery $3.6 \%$, fish and/or seafood $2.1 \%$, milk $1.0 \%$, hen's egg $0.6 \%$ and rye and/or wheat $0.2 \%)$. Most patients had an allergy to various elicitors, and only 11 patients (1.1\%) were suffering from an exclusive non-vegetable food-induced allergic disorder (milk, fish and/or seafood or hen's egg allergy). Among these $11 \mathrm{pa}-$ tients, however, 9 simultaneously presented with positive skin prick test reactions to cross-reacting allergens (e.g. an allergy to house dust mite in seafood-allergic patients).

The majority of the patient cohort (60.4\%) was sensitized to one or more aeroallergens. In $23.4 \%$ of the patients, a sensitization to mugwort could be identified, and according to skin prick test results $19.5 \%$ of the patients were sensitized to ragweed. Larger numbers of sensitizations appeared to be less common than sensitization to only one aeroallergen (fig. 1). There was a strong correlation between the number of co-sensitizations and the corresponding frequency of ragweed sensitization. We performed conjunctival provocation tests in 48 patients who were sensitized to ragweed. Twenty-six (54.2\%) were tested positive for ragweed. Three controls did not react to the conjunctival challenge test.

\section{Independent Predictors of Ragweed Sensitization}

Ragweed sensitization was significantly more common in male patients, in patients whose complaints occurred chiefly during September and October, in those who experienced symptoms during only a few months of the year and in those who were suffering from food allergy (table 1). A stronger predictor for ragweed sensitization was a sensitization to mugwort. The strongest association, however, could be identified for the number of co-sensitization classes with odds ratios ranking between 7 and 70 (fig. 2). The variables 'atopic eczema' and 'time between appearance of first symptoms and office visit' were retained in the final model, but were not relevant. Similarly, the variable 'extent of county ragweed cover' 
Table 1. Results of the final Bayesian model for the probability to be sensitized to ragweed $(\mathrm{n}=977)$

\begin{tabular}{|c|c|c|c|c|}
\hline \multirow{2}{*}{$\begin{array}{l}\text { Variable } \\
\text { Atopic eczema }\end{array}$} & \multirow{2}{*}{$\begin{array}{l}\text { Odds ratio } \\
1.1171\end{array}$} & \multicolumn{2}{|c|}{$95 \%$ credible interval } & \multirow{2}{*}{$\begin{array}{l}\text { Posterior probability for a } \\
\text { positive association (\%) } \\
64.4\end{array}$} \\
\hline & & 0.6564 & 1.6441 & \\
\hline Female gender & 0.6856 & 0.4045 & 0.9977 & 3.6 \\
\hline Food allergy & 1.9777 & 1.1507 & 2.9393 & 99.6 \\
\hline Mugwort sensitization & 5.0197 & 2.5362 & 7.7213 & 100.0 \\
\hline Maximum symptoms in September/October & 4.0333 & 1.3552 & 7.4813 & 100.0 \\
\hline Duration of symptoms within 1 year (months) & 0.8712 & 0.7686 & 0.9722 & 0.9 \\
\hline Regional centre & 0.5148 & 0.1117 & 1.0149 & 5.0 \\
\hline Number of co-sensitization groups & \multicolumn{4}{|c|}{ n.a. (ordinal variable, fig. 2 ) } \\
\hline Extent of county ragweed cover & \multicolumn{4}{|c|}{ n.a. (ordinal variable) } \\
\hline
\end{tabular}

Data were adjusted to the effect of the extent of county ragweed cover. Variables selected according to the DIC are shown. A relevant association can be assumed when the posterior probability for a positive association with a covariate is $>95$ or $<5 \%$, respectively. n.a. = Not applicable.

did not gain relevance. Several other variables ('age', 'history of residential changes', 'need for an anti-allergic medication', 'allergic upper airway disease', 'complaints during summertime' or 'month in which symptoms had been experienced') were not included in the final model, emphasizing that these covariates were unimportant.

We also constructed a second model, in which we replaced the variable 'extent of county ragweed cover' by the variable 'county of residence'. The corresponding results of the final model were qualitatively and also quantitatively almost identical to the first model. A relevant association with a specific county could not be identified. Posterior probabilities of a positive association with ragweed sensitization risk varied between 28 and $41 \%$ (fig. 3). According to the statistical methods used, a significant association between the dependent and an independent variable can only be assumed, if corresponding posterior probabilities are $<5$ or $>95 \%$.

\section{Independent Predictors for a Ragweed Sensitization in Patients from the Munich Centre}

In the Munich centre $(\mathrm{n}=873)$, a more subtle analysis of co-sensitizations and an extended diagnosis of ragweed sensitization had been possible, justifying a separate analysis. In that model, we specifically tested the relevance of the categorical variable 'residential area'. The final multivariate model (table 2) yielded results which were almost identical to those obtained for the whole cohort. Again, we found an extraordinarily strong association between ragweed sensitization and the extent of polysensitization. The risk of being sensitized to ragweed steadily and significantly increased with the number of

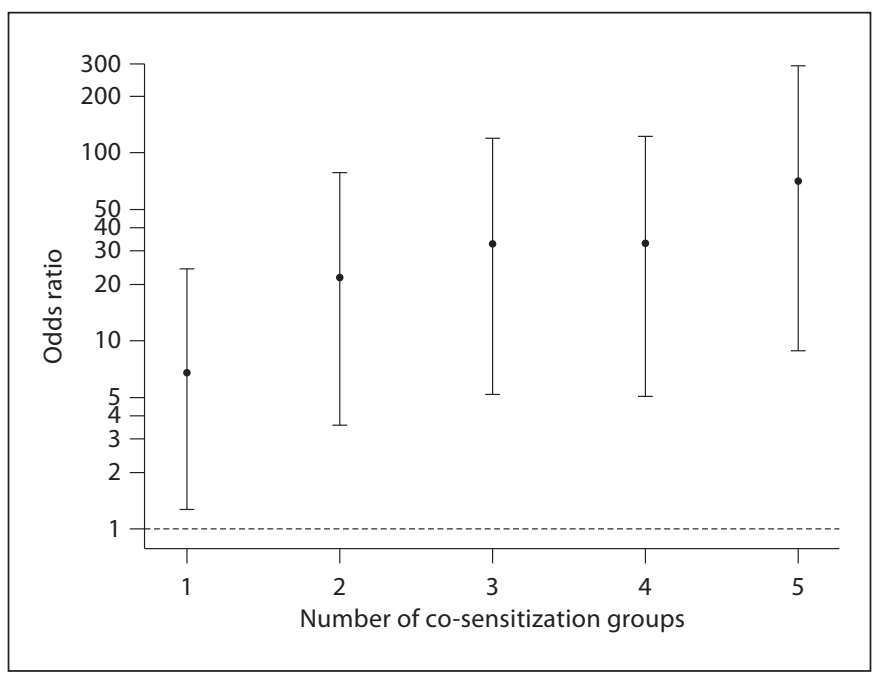

Fig. 2. Covariate-adjusted association between the number of cosensitization groups (except ragweed) and the risk of becoming sensitized to ragweed $(n=977)$. Odds ratio refers to subjects not sensitized to any aeroallergen.

additional positive reactions to other common aeroallergens (fig. 4). On the other hand, variables reflecting residential areas (suburban, rural) were part of the final model, but did not gain sufficient relevance when compared to the reference category (urban residence). In that model, we also retested the importance of the variable 'extent of county ragweed cover' for ragweed sensitization (by replacing the variable 'residential area'). As for the whole cohort, no relevant associations could be found, and all other predictors were also virtually identical. 


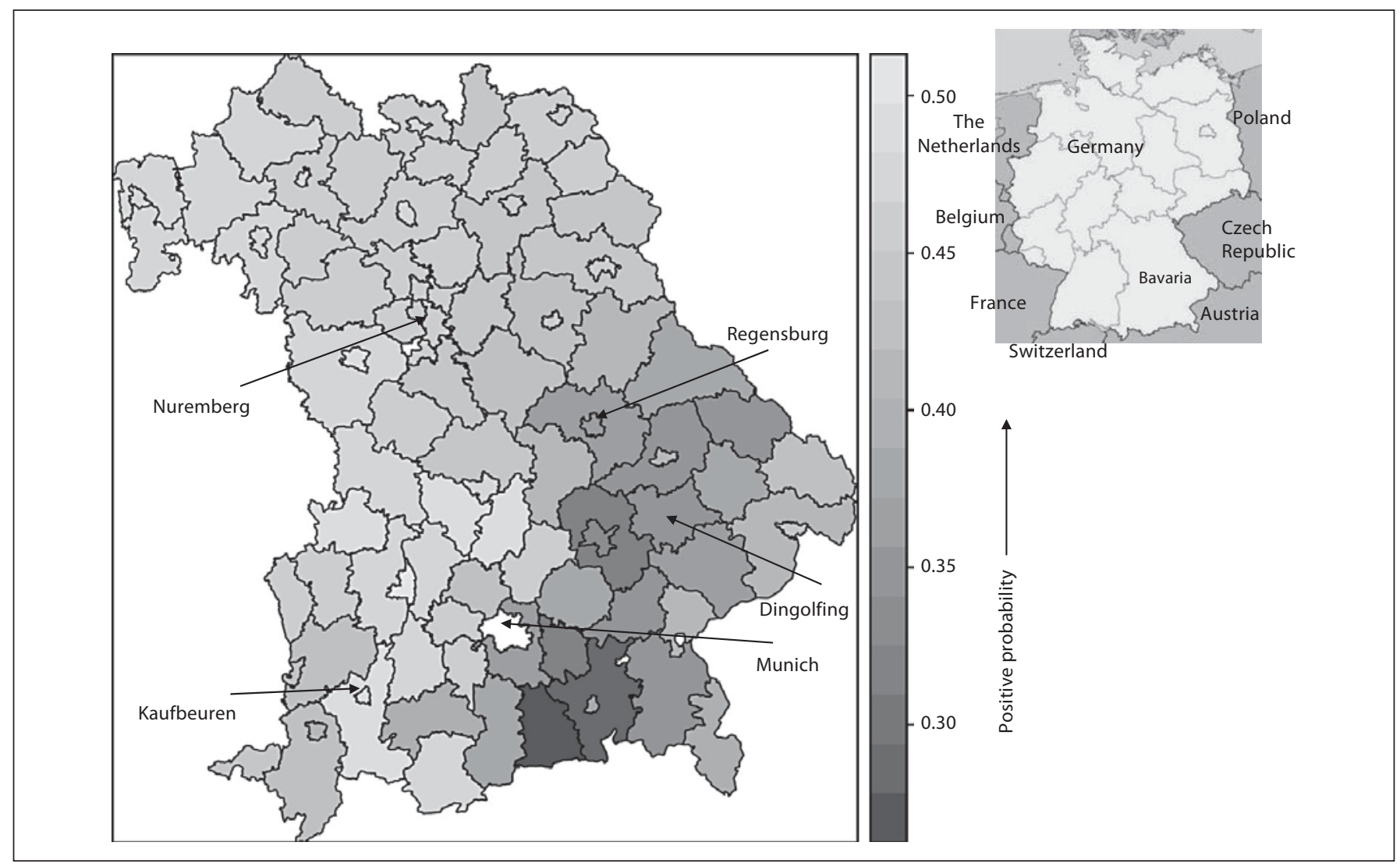

Fig. 3. Covariate-adjusted association between county of residence (Bavaria) and the risk of becoming sensitized to ragweed $(\mathrm{n}=977)$. Numbering of the gray scale indicate posterior probabilities for a positive association with ragweed sensitization risk. Reference category for the risk of becoming sensitized to ragweed is the area defined by Munich city-limits (arrow). The lowest pos- terior probability (as indicated by the darkest gray) was identified for Miesbach county (0.28). A significant positive association between ragweed sensitization and county of residence can only be assumed, if corresponding posterior probabilities are $<0.05$. ( $\mathrm{I}=$ City of Nuremberg, II = city of Munich).

\section{Discussion}

Our study is the first to evaluate the importance of a variety of suspected clinical, environmental and geographical risk factors for acquiring a ragweed sensitization in a high-risk population. This population comprised adult patients with a suspected or documented allergic upper airway disease, atopic eczema, or food allergy.

In our largely south Bavarian cohort, about $20 \%$ of the patients tested positive for ragweed. According to a recent European epidemiological study, the average pan-European frequency of ragweed sensitization in high-risk patients was $14.1 \%$. Similar rates were found in patients from 3 German allergy centres [13], but variations between different European countries were extremely high (2-54\%).
The high frequency of ragweed sensitization presumably results from 2 different phenomena. Firstly, it is possible that a portion of patients sensitized to ragweed acquired this sensitization via cross-reactivity to mugwort. This hypothesis is supported by our finding that mugwort sensitization was the second strongest, independent predictor for a ragweed sensitization (topped only by the extent of polysensitization) (tables 1 and 2: corresponding odds ratios). Primary ragweed sensitization is, however, a more likely explanation for our findings because regional allergen exposure increased throughout the last two decades. Long-term observation data from Vienna, Austria showed that, among patients with inhalative allergic diseases, the frequency of ragweed-specific IgE antibodies had risen from $20 \%$ in the late 1980s to about $30 \%$ at the end of the 1990s [9]. These findings correlate 
Table 2. Results of the final Bayesian model for the probability to be sensitized to ragweed

\begin{tabular}{|c|c|c|c|c|}
\hline \multirow{2}{*}{$\begin{array}{l}\text { Variable } \\
\text { Atopic eczema }\end{array}$} & \multirow{2}{*}{$\begin{array}{l}\begin{array}{l}\text { Odds } \\
\text { ratio }\end{array} \\
1.1419\end{array}$} & \multicolumn{2}{|c|}{ 95\% credible interval } & \multirow{2}{*}{$\begin{array}{l}\text { Posterior probability for a } \\
\text { positive association (\%) }\end{array}$} \\
\hline & & 0.6485 & 1.6543 & \\
\hline Food allergy & 1.6792 & 0.9577 & 2.4582 & 98.3 \\
\hline Mugwort sensitization & 4.6879 & 2.5960 & 7.2685 & 100.0 \\
\hline Maximum symptoms in September/October & 2.3241 & 0.7806 & 4.4014 & 96.4 \\
\hline Residential area: suburban & 0.9023 & 0.2910 & 1.6183 & 32.8 \\
\hline Residential area: rural & 1.3512 & 0.7887 & 1.9549 & 89.1 \\
\hline Time between appearance of first symptoms and office visit (years) & & & n.a. (smoothe & model) \\
\hline Number of co-sensitization groups & & & n.a. (ordinal & riable, fig. 4) \\
\hline
\end{tabular}

Only data from the Munich centre were analyzed $(n=873)$. Data were adjusted to the effect of the residential areas. Urban place of residence was the reference category. Variables selected according to the DIC are shown. A relevant association can be assumed when the posterior probability for a positive association with a covariate is $>95$ or $<5 \%$, respectively. n.a. $=$ Not applicable.

well with a 3-times-elevated annual ragweed pollen load over the same period of time. Correspondingly, ragweed pollen allergy is also quite a recent phenomenon. In northern Italy, the presence of ragweed had been reported in the area of Turin since the beginning of the 1980s; however, it was only at the end of that decade that ragweed allergy began its dramatic increase, starting in the surroundings of Milan [4]. Ragweed sensitization may also be relevant from a clinical point of view. This is evident from the preliminary results of our study concerning the frequency of ragweed allergy in patients sensitized to ragweed. Among the patients on whom we could also perform a conjunctival provocation test, $54.2 \%$ tested positive for ragweed.

In our study, the most important determinant for a ragweed sensitization was the number of sensitizations towards other aeroallergen groups (polysensitization). Polysensitization is a distinct phenomenon in atopic diseases, as it is associated with an increased severity of or likelihood for allergic diseases [18-21] and with a familial coincidence suggesting a genetic basis [22, 23]. According to our results, polysensitization may also indicate a high susceptibility on the level of induction of an inhalant allergy. After adjusting to numerous confounders (such as sensitization to mugwort, sex, age, place of residence, environment or the presence of atopic diseases), it was found that with the number of sensitizations to other aeroallergen groups increasing the likelihood of being sensitized to ragweed also increased significantly. This finding is in line with observations by several other descriptive studies showing a similar association for other aeroallergens $[20$,

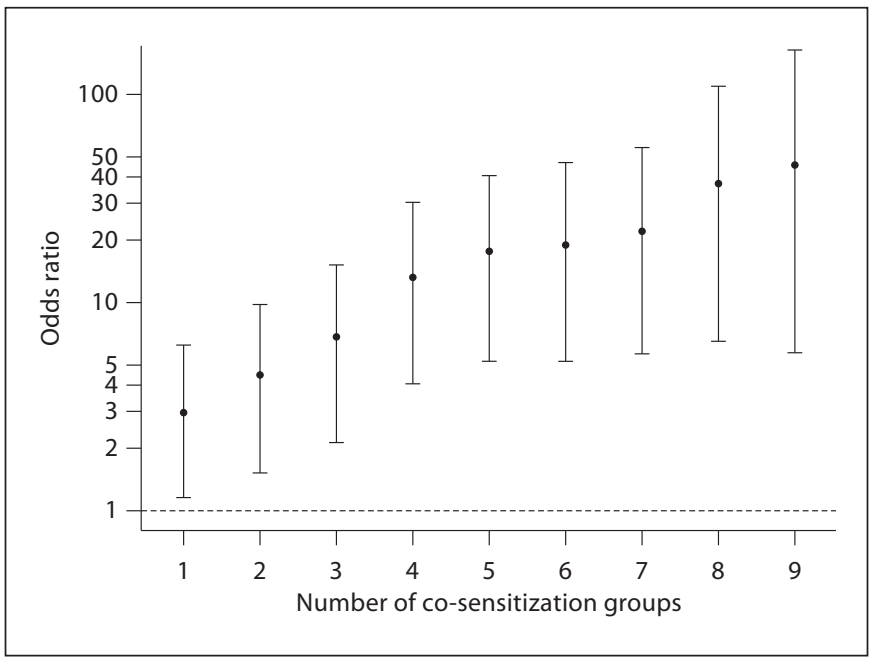

Fig. 4. Covariate-adjusted association between the number of cosensitization groups (except ragweed) and the risk of becoming sensitized to ragweed. Nine groups of aeroallergens were tested (house dust mites, animal dander, molds and pollen from grasses, trees, mugwort, stinging nettle, ash and plantain). Data exclusively refer to patients from the Munich centre, in whom an extended diagnosis was possible $(n=873)$. Odds ratio refers to subjects not sensitized to any aeroallergen.

$24,25]$. The latter longitudinal studies, however, did not adjust the polysensitization effect to other confounders.

According to our multivariate analyses, we can be reasonably certain that this polysensitization effect is independent of other covariables and represents an entity of its own. It appears that patients with multiple sensitiza- 
tions are more readily sensitized to a new aeroallergen. This hypothesis may be compared to experimental and clinical findings in other types of allergy (contact allergy), where there is sufficient evidence that polysensitization is a clinical sign of increased susceptibility towards new allergens [26].

Our findings also add further quantitative elements to the notion of sensitization to an inhalant allergy as being a graded phenomenon, depending not only on exposure dose and allergen potency, but also on graded susceptibility [27]. The molecular basis of this heightened susceptibility consists in the phenomenon of $\mathrm{Th}_{2}$ collateral priming indicating a process, in which $\mathrm{Th}_{2}$ cells specific for one inhaled antigen can facilitate the priming of naive $\mathrm{T}$ cells to unrelated new inhaled allergens, and which is associated with an increase in IL-4 production from peripheral blood mononuclear cells (PBMC) [28]. IL-4 production by in vitro-activated $\mathrm{PBMC}$ is significantly higher in polysensitized than in monosensitized patients, showing that PBMC of mono- and polysensitized subjects have a different IL-4 profile [29].

Several of our other findings deserve specific comment. It is generally believed that people who live in urban areas tend to be more affected by pollen-induced respiratory allergy than people living in rural areas [4]. Furthermore, components of air pollution may enhance the risk of both atopic sensitization and the exacerbation of symptoms in sensitized subjects [4]. On the other hand, it was shown that the ragweed pollen count is lower in cities that in a rural environment [30].

We found that neither the residential area (urban, suburban or rural), nor the county of residence, residential history or the extent of county ragweed cover were significantly associated with ragweed sensitization. These findings seem to be in contrast with the results of a recent observational study from Canada, where it was found that ragweed sensitization was lower in the predominantly rural areas than in urban Canadian cities [31]. There may be various methodological reasons for the differences between this particular study and our findings; it examined healthy adults, whereas we included only patients with suspected or documented atopic diseases. Furthermore, the Canadian study did not make adjustments for the most important confounders for ragweed sensitization, namely mugwort sensitization and the total number of other allergen groups to which subjects might have been simultaneously sensitized.

According to our results, it appears that residential, local geographical or environmental conditions are of minor importance for becoming sensitized to ragweed.
The explanation for the relative unimportance of these local variables can most likely be found in the biology and physical characteristics of ragweed pollen. Ragweed plants produce an enormous amount of pollen, which easily disperses over hundreds of kilometers [4]. In central Italy, several episodes of detection of ragweed pollen appeared to be linked to air masses coming from the Balkan states (possibly Hungary). Correspondingly, in contrast to other aeroallergens, neither the type of residential area nor the local weather conditions were found to correlate with daily ragweed pollen concentrations or average pollen index [30,32]. Since very little ragweed antigen is necessary to become sensitized, there is an increasing trend towards ragweed allergy in neighbouring regions where plants are not present [4]. Consequently, it appears plausible that local geographical confounders are comparatively unimportant for ragweed sensitization. Our results support the notion that ragweed pollen spreads universally, and that its dispersion is much less controlled by local environmental or geographical conditions than that of other aeroallergens.

Finally, we could confirm established covariates predicting a pollen sensitization (gender and food allergy), or a ragweed-specific sensitization (most complaints occurring in September or October) in a high-risk cohort. On the other hand, in our patients, who were all older than 18 years, age did not correlate with the frequency of ragweed sensitization. This finding is surprising because several other cross-sectional studies demonstrated a decreasing frequency of aeroallergen sensitization with greater age $[20,33]$. This age-related immunological deficit does not appear to materialize after ragweed exposure. This observation may highlight the extraordinarily strong allergenic capacity of this antigen which affects old and young high-risk patients to the same extent. A similar phenomenon has also been observed in the northern Italian population, in which the de novo exposure to ragweed resulted in the unexpected sensitization of many older people [34].

The extraordinary allergenic characteristics of ragweed pollen coincide with the dissemination of $A$. artemisiifolia plants throughout central Europe including southern Bavaria. To avoid or limit the formation of new ragweed seeds and the further spread of the ragweed infestation, 3 different anti-ragweed measures and prevention strategies have been proposed. The first concept, which has also been recommended by the World Health Organization concerning the future of allergies [35], propagates the eradication of ragweed. As long-distance travel of ragweed pollen is now widely acknowledged, 
eradication programs limited to particular countries will not succeed and a pan-European action would be needed [36]. Secondly, it may be helpful to treat other inhalant allergies as aggressively as possible to prevent a future ragweed sensitization/allergy via priming mechanisms. This concept is, however, still hypothetical, because the majority of studies (all retrospective in nature) could not demonstrate such a preventive effect [37-40]. Finally, to prevent ragweed-induced symptoms, it has been proposed that informing and educating risk patients would enable them to practice a strategy of allergen avoidance behaviour [41]. Specific preventive measures should be offered to high-risk patients with multiple sensitizations who are more readily sensitized to a new, highly allergenic aeroallergen.

\section{Study Limitations}

The results of our study may not be generalizable because they represent the experience of a single centre and reflect a unique case mix, organization and process of care. Due to the retrospective nature of the study, the results must be interpreted with care and may only be regarded as material to generate hypotheses. Furthermore, we were unable to collect patient-specific data for ragweed allergen exposure during the recruitment period of the study (2006-2009). In Bavaria at that time, only the regional extent of ragweed cover was available as a surrogate variable for ragweed allergen exposure. However, studies have shown a reasonable correlation between the extent of local ragweed cover and ragweed allergen exposure [42]. In addition, the precise allergen concentration in commercially available standard extracts used for con- junctival provocation tests is not known. Therefore, results of corresponding tests might potentially have been obscured by allergen concentrations either too low to produce specific symptoms, or too high, thereby possibly producing unspecific symptoms. Finally, according to a decision of the Institutional Review Board, it was not permitted to include children or adolescents in this pilot study; they might have shown a different predisposition to become sensitized to ragweed.

\section{Acknowledgements}

This study was supported by a grant from the Bavarian State Ministry of the Environment and Public Health. The authors thank Alexander Kienitz, M.D., (Dingolfing), Karl Guggenberger, M.D., (Kaufbeuren) and Ulf Detmar, M.D., (Bad Wörishofen) for their contribution to the data collection, and Dr. Ricarda Eben and Monika Walz for data management. We also thank Wolfgang Hartl, M.D. for the critical revision of the manuscript.

\section{Disclosure Statement}

F.R. was a paid lecturer for ALK-Abelló, HAL, Bencard and Phadia, and participated in studies for ALK-Abelló, Allergopharma and HAL. B.P. was a paid lecturer for ALK-Abelló, Stallergenes and Novartis, and participated in studies for ALK-Abelló, Allergopharma and HAL. M.K. was a paid lecturer for ALK-Abelló, AstraZeneca, Beckmann, GlaxoSmithKline, HAL, Phadia and Novartis and participated in studies for ALK-Abelló, Phadia and Stallergenes.

A.W., J.G., D.S.-B., H.K. and T.H. have no such interests to declare.

\section{References}

1 Björkstén B, Clayton T, Ellwood P, Stewart A, Strachan D, ISAAC Phase III Study Group: Worldwide time trends for symptoms of rhinitis and conjunctivitis: phase III of the International Study of Asthma and Allergies in Childhood. Pediatr Allergy Immunol 2008; 19:110-124.

2 Zizka LH, Caulfield FA: The potential influence of rising atmospheric carbon dioxide $\left(\mathrm{CO}_{2}\right)$ on pollen production of common ragweed as a test case. World Resour Rev 2000; 12:449-457.

3 Wallace DV, Dykewicz MS, Bernstein DI, Blessing-Moore J, Cox L, Khan DA, Lang DM, Nicklas RA, Oppenheimer J, Portnoy JM, Randolph CC, Schuller D, Spector SL, Tilles SA, Joint Task Force on Practice, American Academy of Allergy (Asthma \&
Immunology), American College of Allergy (Asthma and Immunology), Joint Council of Allergy (Asthma and Immunology): The diagnosis and management of rhinitis: an updated practice parameter. J Allergy Clin Immunol 2008;122(2 suppl):S1-S84.

4 D’Amato G, Cecchi L, Bonini S, Nunes C, Annesi-Maesano I, Behrendt H, Liccardi G, Popov T, van Cauwenberge P: Allergenic pollen and pollen allergy in Europe. Allergy 2007;62:976-990.

5 Basset IJ, Crompton CW: The biology of Canadian weeds. II. Ambrosia artemisiifolia L. and A. psilostachya DC. Can J Plant Sci 1975; 55:463-476.

6 Corsico R, Falagiani P, Ariano R, Berra D, Biale C, Bonifazi F, Campi P, Feliziani V, Frenguelli, G, Galimberti M, Gallesio MT,
Liccardi, G, Loreti A, Marcer G, Marcucci F, Meriggi A, Minelli M, Nardelli R, Nardi G, Negrini CA, Papa G, Piu G, Pozzan M, D’Ambrosio FP, Riva G: An epidemiological survey on the allergological importance of some emerging pollens in Italy. J Investig Allergol Clin Immunol 2000;10:155-161.

7 Bousquet PJ, Chinn S, Janson C, Kogevinas M, Burney P, Jarvis D: Geographical variation in the prevalence of positive skin tests to environmental aeroallergens in the European Community Respiratory Health Survey. I. Allergy 2007;62:301-309.

8 Alberternst B, Nawrath S: Spreading and distribution of common ragweed (Ambrosia artemisiifolia) in Germany. Proceedings of the 4th European Symposium on Aerobiology, Turku, 2008. 
9 Jäger S: Ragweed (Ambrosia) sensitization rates correlate with the amount of inhaled airborne pollen. A 14-year study in Vienna, Austria. Aerobiologia 2000;16:149-153.

10 Bernstein IL, Li JT, Bernstein DI, Hamilton R, Spector SL, Tan R, Sicherer S, Golden DB, Khan DA, Nicklas RA, Portnoy JM, BlessingMoore J, Cox L, Lang DM, Oppenheimer J, Randolph CC, Schuller DE, Tilles SA, Wallace DV, Levetin E, Weber R, American Academy of Allergy (Asthma and Immunology), American College of Allergy (Asthma and Immunology): Allergy diagnostic testing: an updated practice parameter. Ann Allergy Asthma Immunol 2008;100(suppl 3):S1-S148.

11 Boyce JA, Assa'ad A, Burks AW, Jones SM, Sampson HA, Wood RA, Plaut M, Cooper SF, Fenton MJ, Arshad SH, Bahna SL, Beck LA, Byrd-Bredbenner C, Camargo CA Jr, Eichenfield L, Furuta GT, Hanifin JM, Jones C, Kraft M, Levy BD, Lieberman P, Luccioli S, McCall KM, Schneider LC, Simon RA, Simons FE, Teach SJ, Yawn BP, Schwaninger JM: Guidelines for the diagnosis and management of food allergy in the United States: report of the NIAID-sponsored expert panel. J Allergy Clin Immunol 2010;126(6 suppl):S1-S58.

12 Alberternst B, Nawrath S, Klingenstein F: Biologie. Verbreitung und Einschleppung von Ambrosia artemisiifolia in Deutschland und Bewertung aus Naturschutzsicht. Nachrichtenbl Deut Pflanzenschutzd 2006;58: 279-285.

13 Heinzerling LM, Burbach GJ, Edenharter G, Bachert C, Bindslev-Jensen C, Bonini, S, Bousquet J, Bousquet-Rouanet L, Bousquet PJ, Bresciani M, Bruno A, Burney P, Canonica GW, Darsow U, Demoly P, Durham S, Fokkens WJ, Giavi S, Gjomarkaj M, Gramiccioni C, Haahtela T, Kowalski ML, Magyar P, Muraközi G, Orosz M, Papadopoulos NG, Röhnelt C, Stingl G, Todo-Bom A, von Mutius E, Wiesner A, Wöhrl S, Zuberbier T: GA $^{2}$ LEN skin test study I: GA ${ }^{2}$ LEN harmonization of skin prick testing: novel sensitization patterns for inhalant allergens in Europe. Allergy 2009;64:1498-1506.

14 Möller C, Bjorksten B, Nilsson G, Dreborg S: The precision of the conjunctival provocation test. Allergy 1984;39:37-41.

15 Gelman A, Carlin JB, Stern HS, Rubin DB: Bayesian Data Analysis. Boca Raton, Chapman \& Hall/CRC, 2004.

16 Belitz C, Brezger A, Kneib T, Lang S: BayesX - software for Bayesian inference in structured additive regression models. Version 2.0. http://www.stat.uni-muenchen.de/ $\sim$ bayesx. 2002.

17 Spiegelhalter DJ, Best NG, Carlin BR, van der Linde A: Bayesian measures of model complexity and fit. J R Stat Soc Series B. 2002;64: 583-616.
18 Kim KW, Kim EA, Kwon BC, Kim ES, Song TW, Sohn MH: Comparison of allergic indices in monosensitized and polysensitized patients with childhood asthma. J Korean Med Sci 2006;21:1012-1016.

19 Schäfer T, Heinrich J, Wjst M, Adam H, Ring J, Wichmann H-E: Association between severity of atopic eczema and degree of sensitization to aeroallergens in schoolchildren. J Allergy Clin Immunol 1999;104:1280-1284. 20 Pallasaho P, Rönmark E, Haahtela T, Sovijärvi AR, Lundbäck B: Degree and clinical relevance of sensitization to common allergens among adults: a population study in Helsinki, Finland. Clin Exp Allergy 2006;36:503-509.

21 Burbach GJ, Heinzerling LM, Edenharter G, Bachert C, Bindslev-Jensen C, Bonini, S, Bousquet J, Bousquet-Rouanet L, Bousquet PJ, Bresciani M, Bruno A, Canonica GW, Darsow U, Demoly P, Durham S, Fokkens WJ, Giavi S, Gjomarkaj M, Gramiccioni C, Haahtela T, Kowalski ML, Magyar P, Muraközi G, Orosz M, Papadopoulos NG, Röhnelt C, Stingl G, Todo-Bom A, von Mutius E, Wiesner A, Wöhrl S, Zuberbier T: GA(2)LEN skin test study II: clinical relevance of inhalant allergen sensitizations in Europe. Allergy 2009;64:1507-1515.

22 Kang H, Yu J, Yoo Y, Kim DK, Koh YY: Coincidence of atopy profile in terms of monosensitization and polysensitization in children and their parents. Allergy 2005;60: 1029-1033.

23 Yoo Y, Yu J, Kim DK, Choi SH, Koh YY: Coincidence of atopy and its profile (monosensitization/polysensitization) between sibling pairs. Ann Allergy Asthma Immunol 2005; 95:433-437.

24 Fasce L, Tosca MA, Baroffio M, Olcese R, Ciprandi G: Atopy in wheezing infants always starts with monosensitization. Allergy Asthma Proc 2007;28:449-453.

25 Silvestri M, Rossi GA, Cozzani S, Pulvirenti G, Fasce L: Age-dependent tendency to become sensitized to other classes of aeroallergens in atopic asthmatic children. Ann Allergy Asthma Immunol 1999;83:335-340.

26 Schnuch A, Brasch J, Uter W: Polysensitization and increased susceptibility in contact allergy: a review. Allergy 2008;63:156-167.

27 Friedmann PS: Graded continuity, or all or none - studies of the human immune response. Clin Exp Dermatol 1991;16:79-84.

28 Dittrich AM, Chen HC, Xu L, Ranney P, Connolly S, Yarovinsky TO, Bottomly HK: A new mechanism for inhalational priming: IL- 4 bypasses innate immune signals. J Immunol 2008;181:7307-7315.

29 Pene J, Rivier A, Lagier B, Becker WM, Michel FB, Bousquet J: Differences in IL-4 release by $\mathrm{PBMC}$ are related with heterogeneity of atopy. Immunology 1994;81:58-64.

30 Sikoparija B, Radisic P, Pejak T, Simic S: Airborne grass and ragweed pollen in the southern Panonnian Valley - consideration of rural and urban environment. Ann Agric Environ Med 2006;13:263-266.
31 Chan-Yeung M, Anthonisen NR, Becklake MR, Bowie D, Sonia Buist A, Dimich-Ward H, Ernst P, Sears MR, Siersted HC, Sweet L, Van Til L, Manfreda J: Geographical variations in the prevalence of atopic sensitization in six study sites across Canada. Allergy 2010;65:1404-1413.

32 Kasprzyk I: Non-native Ambrosia pollen in the atmosphere of Rzeszów (SE Poland): evaluation of the effect of weather conditions on daily concentrations and starting dates of the pollen season. Int J Biometeorol 2008;52: 341-351.

33 Kerkhof M, Postma DS, Schouten JP, de Monchy JG: Allergic sensitization to indoor and outdoor allergens and relevance to bronchial hyperresponsiveness in younger and older subjects. Allergy 2003;58:1261-1267.

34 Asero R: Birch and ragweed pollinosis north of Milan: a model to investigate the effects of exposure to 'new' airborne allergens. Allergy 2002;57:1063-1066.

$35 \mathrm{WHO} / \mathrm{ICIS} / \mathrm{EPN}$ : Phenology and human health: allergic disorders. WHO Meeting report, Rome, 2003, 56 pp. http://www.pollenwarndienst.at/upload/images/original/719. pdf.

36 Burbach GJ, Heinzerling LM, Röhnelt C, Bergmann KC, Behrendt $\mathrm{H}$, Zuberbier T: Ragweed sensitization in Europe - GA(2) LEN study suggests increasing prevalence. Allergy 2009;64:664-665.

37 Asero R: Pollen specific immunotherapy is not a risk factor for de novo sensitization to cross-reacting allergens in monosensitized subjects. J Investig Allergol Clin Immunol 2006;16:253-257.

38 Asero R: Injection immunotherapy with different airborne allergens did not prevent de novo sensitization to ragweed and birch pollen north of Milan. Int Arch Allergy Immunol 2004;133:49-54.

39 Harmanci K, Razi CH, Toyran M, Kanmaz G, Cengizlier MR: Evaluation of new sensitizations in asthmatic children monosensitized to house dust mite by specific immunotherapy. Asian Pac J Allergy Immunol 2010; 28:7-13.

40 Tella R, Bartra J, San Miguel M, Olona M, Bosque M, Gaig P, Garcia-Ortega P: Effects of specific immunotherapy on the development of new sensitisations in monosensitised patients. Allergol Immunopathol (Madr) 2003;31:221-225.

41 Laaidi M, Laaidi K, Besancenot JP, Thibaudon M: Ragweed in France: an invasive plant and its allergenic pollen. Ann Allergy Asthma Immunol 2003;91:195-201.

42 Fumanal B, Chauvel B, Bretagnolle F: Estimation of pollen and seed production of common ragweed in France. Ann Agric Environ Med 2007;14:233-236. 